\title{
GAIA Level 3 Gestational Diabetes Mellitus
}

National Cancer Institute

\section{Source}

National Cancer Institute. GAIA Level 3 Gestational Diabetes Mellitus. NCI Thesaurus.

Code C128755.

GAIA Level 3 Gestational Diabetes Mellitus is defined by three criteria: first, absence of pre-gestational diabetes [pre-gestational diabetes is defined as a) previous diagnosis of diabetes while not pregnant OR b) first trimester hemog lobin A1c level of greater than or equal to $6.5 \%(47.5 \mathrm{mmol} / \mathrm{mol}) \mathrm{OR} \mathrm{c})$ first trimester fasting blood glucose greater than or equal to $126 \mathrm{mg} / \mathrm{dL}(7 \mathrm{mmol} / \mathrm{L})]$; second, gestational age with at least level 3 certainty, using the GAIA definition for gestational age; third, the diagnosis of gestational diabetes as determined by fasting plasma glucose of 5.1-6.9 mmol/L (92-125 mg/dL) using either venous or capillary blood samples. 